\title{
A mitotically active, cellular tumor stroma and/ or inflammatory cells associated with tumor cells may contribute to intermediate or high Oncotype DX Recurrence Scores in low-grade invasive breast carcinomas
}

\author{
Geza Acs $^{1,2,3,4}$, Nicole N Esposito ${ }^{1,2,3}$, John Kiluk ${ }^{2}$, Loretta Loftus ${ }^{2}$ and Christine Laronga ${ }^{2}$ \\ ${ }^{1}$ Department of Anatomic Pathology, Moffitt Cancer Center, Tampa, FL, USA; ${ }^{2}$ Department of Women's \\ Oncology, Comprehensive Breast Program, Moffitt Cancer Center, Tampa, FL, USA; ${ }^{3}$ Department of Pathology \\ and Cell Biology, University of South Florida College of Medicine, Tampa, FL, USA and ${ }^{4}$ Women's Pathology \\ Consultants, Ruffolo Hooper \& Associates, Tampa, FL, USA
}

\begin{abstract}
Oncotype DX is an RT-PCR-based 21-gene assay validated to provide prognostic and predictive information in the form of a Recurrence Score in patients with estrogen receptor-positive, lymph node-negative breast cancer. Although the Recurrence Score was shown to correlate with several histopathological tumor features, there is a significant proportion of cases showing an apparent discrepancy between Recurrence Score and risk estimates based on the traditional clinicopathological tumor features. In this study, we tested whether a proliferating, cellular stroma and/or admixed inflammatory cells may result in an artificially increased Recurrence Score in low-grade invasive breast cancers. We analyzed the histopathological features in 141 low-grade invasive breast carcinomas, including 41 special type (tubular, cribriform and mucinous) carcinomas, with available Recurrence Score. The tumor stroma was evaluated for increased cellularity and presence of inflammatory cells. Double immunohistochemical stains for pancytokeratin and $\mathrm{Ki}-67$ was performed to assess the cell proliferation in tumor vs stromal/inflammatory cells. The clinicopathological features of tumors with Recurrence Score $<\mathbf{1 8}$ (low risk) were compared with those with Recurrence Score $\geq 18$ (intermediate/high risk). Carcinomas associated with Recurrence Score $\geq \mathbf{1 8}$ showed lower progesterone receptor immunoreactivity, increased stromal cellularity and presence of inflammatory cells associated with the tumor. Double immunohistochemical stains showed significantly increased proliferation in stromal/inflammatory cells compared with carcinoma cells in cases associated with Recurrence Score $\geq 18$. A Ki-67-positive stromal/ tumor cells ratio of $>1$ predicted Recurrence Score $\geq 18$ with an area under the curve of 0.8967 on receiver operator curve analysis $(P<\mathbf{0 . 0 0 0 1})$. Our results suggest that the presence of increased stromal cellularity and/ or associated inflammatory cells in low-grade invasive breast carcinomas may contribute to an apparently increased risk of recurrence according to Oncotype DX Recurrence Score. Careful assessment and correlation with histopathological features in such cases may help in determining the appropriate patient management. Modern Pathology (2012) 25, 556-566; doi:10.1038/modpathol.2011.194; published online 16 December 2011
\end{abstract}

Keywords: breast carcinoma; cell proliferation; Ki-67; oncotype DX; recurrence Score; tumor stroma

Correspondence: Dr G Acs, MD, PhD, Department of Anatomic Pathology, Moffitt Cancer Center, 12902 Magnolia Drive, Tampa, FL 33612, USA.

E-mail: geza.acs@moffitt.org

This work has been presented in part at the 100th Annual Meeting of the United States and Canadian Academy of Pathology, San Antonio, TX, USA, February 26 March 4, 2011.

Received 22 July 2011; revised 11 October 2011; accepted 11 October 2011; published online 16 December 2011
Breast cancer is a heterogeneous disease with a wide range of biological features and clinical behavior. ${ }^{1-3}$ Recognizing their phenotypic diversity, pathologists have classified breast carcinomas into clinically and biologically meaningful groups based on histopathological features, defined by histological grade and type. ${ }^{4-9}$ Histological grade is a measurement of the intrinsic biological features of cancers, which, based on the assessment of the degree of differentiation 
(gland formation and nuclear pleomorphism) and proliferative activity, is a morphological reflection of the perceived aggressiveness of tumors. ${ }^{9,10}$ The prognostic value of the modified combined histological (Nottingham) grade has been established and validated in multiple large independent studies ${ }^{11-21}$ and has been incorporated into prognostic algorithms ${ }^{22-24}$ and clinical guidelines. ${ }^{25}$ Pathologists have also identified specific architectural and cytological patterns the constellation of which defines special types of breast carcinoma. ${ }^{26-28}$ Importantly, histological grade and type provide complementary information about the features of breast cancers. ${ }^{14,29}$ Indeed, the main reason for recognizing special types of breast carcinoma is the improvement of prediction of the likely biological behavior beyond that provided by traditional prognostic factors. ${ }^{26,28,30}$ Women diagnosed with most special type (ie, tubular, cribriform or mucinous) carcinomas have an excellent prognosis, often approaching that of the general population of the same age. ${ }^{26-28}$

Traditionally, beside patient characteristics (ie, age), oncologists have relied on established clinical and histopathological tumor features (size, histological grade, lymph node, hormone receptor, HER2 status) to assess risk of recurrence and guide recommendations for adjuvant chemotherapy. However, such treatment decisions remain challenging, especially with estrogen receptor (ER)-positive early stage tumors where the absolute benefit of chemotherapy is difficult to perceive. As only about $15 \%$ of such patients treated with hormonal therapy alone will recur over 10 years, it is estimated that $85 \%$ of these patients would be exposed to the risks of adjuvant chemotherapy without deriving a significant benefit from it, if chemotherapy was given. ${ }^{31}$ Although the current clinical and histopathological prognostic/predictive factors show strong association with treatment response and outcome, increasing concerns exist that they neither adequately capture the diversity of clinical behaviors of breast cancer nor guide individualized treatment recommendations.

In recent years, the extent of heterogeneity of breast cancers was highlighted by gene expression profiling studies identifying the molecular subgroups, ${ }^{32-34}$ and multiple molecular assays were developed to identify signatures associated with prognosis $^{35-37}$ and response to therapy. ${ }^{38}$ The currently most widely used such assay in the United States is Oncotype DX (Genomic Health, Redwood City, CA, USA), an RT-PCR-based assay, which analyzes 16 cancer-related and 5 reference genes to provide a Recurrence Score. The Recurrence Score is based on the assumption that patients will receive adjuvant hormonal manipulation and predicts a 10year distant recurrence risk as a continuous variable. It is also subdivided into three risk categories: low $(<18)$, intermediate, ${ }^{18-30}$ and high $(>30)$ scores.

Although the Recurrence Score has been validated in multiple studies including thousands of patients ${ }^{31,39-42}$ and has been incorporated into clinical guidelines for management of breast cancer, $^{43}$ several questions remain unanswered. Although the Recurrence Score was shown to predict outcome and response to therapy when analyzing large numbers of cases, its prognostic/ predictive accuracy in a given individual patient has not been adequately addressed and little has been done to study the possibility that some cases may have a falsely low or high Recurrence Score when compared with what would be expected based on routine pathological features and/or outcome. ${ }^{44}$ In addition, the reproducibility of the assay performed with tissue extracts without microdissection of cancer cells from the stroma is not well established, and several studies suggest that the stromal and intimately associated inflammatory cells, especially when mitotically active, can have a significant effect on the Recurrence Score.$^{3,44,45}$ It should also be noted that, in part due to the high cost of the test, no studies validating to the reproducibility and utility of the Oncotype DX assay are available that are independent of Genomic Health.

We have noticed in our clinical practice that a significant proportion of low-grade invasive ductal and special type (tubular, cribriform and mucinous) carcinomas are reported to have intermediate or even high Recurrence Score, which is in contrast with what would be expected based on clinicopathological features and outcome data from years of clinical experience. ${ }^{46-51}$ We have also noted that many such cancers are associated with a cellular tumor stroma admixed with inflammatory cells. Although Genomic Health dissects out biopsy sites from the tumor samples, as they were shown to affect Recurrence Score, ${ }^{45}$ cellular tumor stroma and inflammatory cells associated with the cancer cells are included in the assay. We tested the hypothesis that such cellular stroma and/or inflammatory cells intimately admixed with tumor cells may contribute to an artificially increased Recurrence Score in low-grade invasive breast cancers.

\section{Materials and methods}

We selected 141 consecutive patients with early stage, ER-positive, low-grade invasive breast carcinoma who underwent Oncotype DX testing between 1 January 2006 and 31 March 2011. All hematoxylin- and eosin-stained slides were prospectively reviewed to establish the diagnoses, including histological type and grade, based on established criteria. ${ }^{9,27,52}$ All invasive carcinomas were graded according to the modified combined histological grading system. ${ }^{9,10}$ The number of mitoses was determined in 10 consecutive highpower $(400 \times)$ fields in the mitotically most active areas of tumors. In addition, the tumor 
Table 1 Summary of clinicopathological features

\begin{tabular}{|c|c|c|}
\hline & $\begin{array}{l}\text { All carcinomas } \\
\quad(\mathrm{n}=141)\end{array}$ & $\begin{array}{l}\text { Special type } \\
\text { carcinomas } \\
(\mathrm{n}=41)\end{array}$ \\
\hline $\begin{array}{l}\text { Age (years, median, } \\
\text { mean } \pm \text { s.e.m.) }\end{array}$ & $56(56.9 \pm 0.9)$ & $52(56.2 \pm 1.9)$ \\
\hline $\begin{array}{l}\text { Tumor size (cm, median, } \\
\text { mean } \pm \text { s.e.m.) }\end{array}$ & $1.3(1.4 \pm 0.05)$ & $1.2(1.3 \pm 0.09)$ \\
\hline \multicolumn{3}{|l|}{ Menopausal status (\%) } \\
\hline Premenopausal & $53(38)$ & $20(49)$ \\
\hline Postmenopausal & $88(62)$ & $21(51)$ \\
\hline \multicolumn{3}{|l|}{ Histological type (\%) } \\
\hline Ductal (NST) & $97(68)$ & N/A \\
\hline Lobular & $3(2)$ & \\
\hline Tubular & $25(18)$ & 25 \\
\hline Cribriform & $11(8)$ & 11 \\
\hline Mucinous & $5(4)$ & 5 \\
\hline \multicolumn{3}{|l|}{ Tubule formation (\%) } \\
\hline 1 & $38(27)$ & $29(71)$ \\
\hline 2 & $98(69)$ & $12(29)$ \\
\hline 3 & $5(4)$ & $0(0)$ \\
\hline \multicolumn{3}{|l|}{ Nuclear pleomorphism (\%) } \\
\hline 1 & $29(21)$ & $21(51)$ \\
\hline 2 & $111(78)$ & $20(49)$ \\
\hline 3 & $1(1)$ & $0(0)$ \\
\hline \multicolumn{3}{|l|}{ Mitotic activity (\%) } \\
\hline 1 & $141(100)$ & $41(100)$ \\
\hline 2 & $0(0)$ & $0(0)$ \\
\hline 3 & $0(0)$ & $0(0)$ \\
\hline $\begin{array}{l}\text { Number of mitoses per } 10 \mathrm{HPF} \\
\text { (median, mean } \pm \text { s.em.) }\end{array}$ & $1(1.8 \pm 0.15)$ & $1(1.4 \pm 0.2)$ \\
\hline \multicolumn{3}{|l|}{ Lymphatic invasion (\%) } \\
\hline Absent & $136(96)$ & $41(100)$ \\
\hline Present & $5(4)$ & $0(0)$ \\
\hline \multicolumn{3}{|l|}{$p N$ stage (\%) } \\
\hline $0(\mathrm{i}-)$ & $122(87)$ & $40(98)$ \\
\hline $0(\mathrm{i}+)$ & $9(6)$ & $1(2)$ \\
\hline $1 \mathrm{mi} / 1 \mathrm{a}$ & $10(7)$ & $0(0)$ \\
\hline $\begin{array}{l}\text { Percent ER reactivity } \\
\text { (median, mean } \pm \text { s.e.m.) }\end{array}$ & $100(94.7 \pm 0.7)$ & $100(94.9 \pm 1.3)$ \\
\hline $\begin{array}{l}\text { ER H-score (median, } \\
\text { mean } \pm \text { s.e.m.) }\end{array}$ & $285(274.7 \pm 3.1)$ & $300(276.8 \pm 5.5)$ \\
\hline $\begin{array}{l}\text { Percent PR reactivity } \\
\text { (median, mean } \pm \text { s.e.m.) }\end{array}$ & $90(77.2 \pm 2.3)$ & $90(74.3 \pm 4.9)$ \\
\hline $\begin{array}{l}\text { PR H-score (median, } \\
\text { mean } \pm \text { s.e.m.) }\end{array}$ & $240(209.1 \pm 7.4)$ & $240(202.9 \pm 15.1)$ \\
\hline \multicolumn{3}{|l|}{ HER2 status (\%) } \\
\hline Negative & $141(100)$ & $41(100)$ \\
\hline Positive & $0(0)$ & $0(0)$ \\
\hline \multicolumn{3}{|l|}{ Biopsy site (\%) } \\
\hline Absent & $107(76)$ & $34(83)$ \\
\hline Present & $34(24)$ & $7(17)$ \\
\hline \multicolumn{3}{|l|}{ Cellular stroma (\%) } \\
\hline Absent & $104(74)$ & $28(68)$ \\
\hline Present & $37(26)$ & $13(32)$ \\
\hline \multicolumn{3}{|l|}{ Inflammatory cells (\%) } \\
\hline Absent & $108(77)$ & $29(71)$ \\
\hline Present & $33(23)$ & $12(29)$ \\
\hline
\end{tabular}

Abbreviations: ER, estrogen receptor; H-score, histological score; HPF, high-power field; NST, no special type; PR, progesterone receptor; s.e.m., standard error of the mean. stroma was evaluated for increased cellularity ( $v s$ a more dense, fibrous stroma), presence of inflammatory cells intimately associated with tumor and/ or tumor stroma and presence of prior biopsy site (in the tumor block submitted for Oncotype DX testing).

The clinicopathological features of the tumors are summarized in Table 1. Surgical treatment consisted of lumpectomy in $94(67 \%)$ patients, while 47 (43\%) patients underwent mastectomy. Axillary lymph node staging was performed in all cases and consisted of sentinel lymph node biopsy in 136 $(96 \%)$ cases, while axillary lymph node dissection was performed in $5(4 \%)$ cases, respectively. The median number of lymph nodes per case examined was 2 (range 1-22). Axillary lymph node micrometastases (pN1mi) was present in $10(7 \%)$ patients, while isolated tumor cells $(\mathrm{pNo}(\mathrm{i}+))$ were present in $9(6 \%)$ patients. The median number of positive lymph nodes was 1 (range 1-2). ER and progesterone receptor (PR) status were evaluated by immunohistochemistry (SP1 and 1E2 rabbit monoclonal antibodies, respectively, ultraVIEW ${ }^{\mathrm{TM}} \mathrm{DAB}$ detection system on Benchmark XT, Ventana, Tucson, AZ, USA). In addition to categorical (positive vs negative) results, ER and PR expressions were also assessed using a semi-quantitative immunohistochemical score (H-score) ${ }^{53,54}$ taking in consideration the extent and intensity of nuclear immunoreactivity. Briefly, the $\mathrm{H}$-score was calculated as follows: $\mathrm{H}$-score $=$ sum of $1 \times$ percentage of weak, $2 \times$ percentage of moderate and $3 \times$ percentage of strong staining with score ranges from 0 to 300 . HER2/neu overexpression and/or gene amplification were determined by immunohistochemistry alone (4B5 rabbit monoclonal antibody, ultraVIEW ${ }^{\mathrm{TM}}$ detection system on Benchmark XT, Ventana) in 33 $(23 \%)$ cases, fluorescence in situ hybridization (FISH) alone (PathVysion dual color FISH, Vysis, Downers Grove, IL, USA) in 18 (13\%) cases, or by both methods in $90(64 \%)$ cases. A total of $12(9 \%)$ cases had equivocal HER2 immunohistochemical results, none of which showed gene amplification by FISH. At a mean follow-up time of 27 (range 2-62) months, no tumor recurrence was observed in any of the patients. The study protocols were approved by the University of South Florida Institutional Review Board.

The tumor tissue block used for Oncotype DX testing was used for immunohistochemical assays in each case. A double immunohistochemical stain for pancytokeratin and Ki-67 was performed to assess cell proliferation in cancer vs stromal/inflammatory cells. Briefly, for pancytokeratin (mouse, clone AE1/AE3/PCK26, Ventana, predilute) and Ki-67 (clone 30-9, rabbit monoclonal, Ventana, predilute) immunostaining, heat induced antigen retrieval was performed using an EDTA-based retrieval solution, $\mathrm{pH}=8$, for 16 and $32 \mathrm{~min}$, respectively. Immunohistochemical staining was performed on a Ventana Benchmark XT machine, according to the 
Table 2 Correlation of clinicopathological tumor features with Oncotype DX Recurrence Score in low-grade invasive and special type (tubular, cribriform and mucinous) breast carcinomas

\begin{tabular}{|c|c|c|c|c|c|c|}
\hline & \multicolumn{3}{|c|}{ All cases $(\mathrm{n}=141)$} & \multicolumn{3}{|c|}{ Special type carcinomas $(\mathrm{n}=41)$} \\
\hline & $R S<18(\mathrm{n}=101)$ & $R S \geqslant 18(\mathrm{n}=40)$ & $\mathrm{P}$ & $R S<18(\mathrm{n}=29)$ & $R S \geqslant 18(\mathrm{n}=12)$ & $\mathrm{P}$ \\
\hline Age (years, median, mean \pm s.e.m.) & $56(56.5 \pm 1.0)$ & $54(57.9 \pm 1.9)$ & $0.5217^{*}$ & $52(54.6 \pm 2.1)$ & $54(60.2 \pm 4.0)$ & 0.1804 * \\
\hline $\begin{array}{l}\text { Tumor size (cm, median, } \\
\text { mean } \pm \text { s.e.m.) }\end{array}$ & $1.3(1.4 \pm 0.1)$ & $1.2(1.3 \pm 0.1)$ & $0.6990^{*}$ & $1.3(1.3 \pm 0.1)$ & $1.15(1.3 \pm 0.2)$ & $0.9747^{*}$ \\
\hline \multicolumn{7}{|l|}{ Menopausal status (\%) } \\
\hline Premenopausal & $37(37)$ & $16(40)$ & $0.7049^{* *}$ & $14(48)$ & $6(50)$ & $1.000^{* *}$ \\
\hline Postmenopausal & $64(63)$ & $24(60)$ & & $15(52)$ & $6(50)$ & \\
\hline \multicolumn{7}{|l|}{ Histological type (\%) } \\
\hline Ductal (NST) & $70(69)$ & $27(67)$ & $0.9674^{* *}$ & N/A & & \\
\hline Lobular & $2(2)$ & $1(3)$ & & & & \\
\hline Other special type & $29(29)$ & $12(30)$ & & & & \\
\hline \multicolumn{7}{|l|}{ Tubule formation (\%) } \\
\hline 1 & $29(29)$ & $9(23)$ & $0.6652^{* *}$ & $22(76)$ & $7(58)$ & $0.2847^{* *}$ \\
\hline 2 & $69(68)$ & $29(72)$ & & $7(24)$ & $5(42)$ & \\
\hline 3 & $3(3)$ & $2(5)$ & & $0(0)$ & $0(0)$ & \\
\hline \multicolumn{7}{|l|}{ Nuclear pleomorphism (\%) } \\
\hline 1 & $22(22)$ & $7(18)$ & $0.6864^{* *}$ & $16(55)$ & $5(42)$ & $0.5055^{* *}$ \\
\hline 2 & $78(77)$ & $33(82)$ & & $13(45)$ & $7(58)$ & \\
\hline 3 & $1(1)$ & $0(0)$ & & $0(0)$ & $0(0)$ & \\
\hline \multicolumn{7}{|l|}{ Mitotic activity (\%) } \\
\hline 1 & $101(100)$ & $40(100)$ & N/A & $101(100)$ & $40(100)$ & N/A \\
\hline 2 & $0(0)$ & $0(0)$ & & $0(0)$ & $0(0)$ & \\
\hline 3 & $0(0)$ & $0(0)$ & & $0(0)$ & $0(0)$ & \\
\hline $\begin{array}{l}\text { Number of mitoses per } 10 \mathrm{HPF} \\
\text { (median, mean } \pm \text { s.e.m.) }\end{array}$ & $1(1.8 \pm 0.2)$ & $1(1.7 \pm 0.3)$ & $0.7901^{*}$ & $1(1.3 \pm 0.2)$ & $1(1.7 \pm 0.6)$ & $0.4548^{*}$ \\
\hline \multicolumn{7}{|l|}{ Lymphatic invasion (\%) } \\
\hline Absent & $96(95)$ & $39(97)$ & 0.6750 ** & $29(100)$ & $12(100)$ & N/A \\
\hline Present & $5(5)$ & $1(3)$ & & $0(0)$ & $0(0)$ & \\
\hline \multicolumn{7}{|l|}{ pN stage (\%) } \\
\hline $0(\mathrm{i}-)$ & $86(85)$ & $36(90)$ & $0.4941^{* *}$ & $28(97)$ & $12(100)$ & N/A \\
\hline $0(\mathrm{i}+)$ & $8(8)$ & $1(3)$ & & $1(3)$ & $0(0)$ & \\
\hline $1 \mathrm{mi} / 1 \mathrm{a}$ & $7(7)$ & $3(7)$ & & $0(0)$ & $0(0)$ & \\
\hline $\begin{array}{l}\text { Percent ER reactivity (median, } \\
\text { mean } \pm \text { s.e.m.) }\end{array}$ & $100(95.2 \pm 0.8)$ & $100(93.5 \pm 1.6)$ & $0.8216^{*}$ & $100(95.3 \pm 1.5)$ & $100(93.8 \pm 2.8)$ & $0.9367^{*}$ \\
\hline ER H-score (median, mean \pm s.e.m.) & $285(277.2 \pm 3.4)$ & $285(268.1 \pm 7.2)$ & $0.5214^{*}$ & $300(279.7 \pm 6.1)$ & $292.5(270.0 \pm 11.8)$ & $0.5742 *$ \\
\hline $\begin{array}{l}\text { Percent PR reactivity (median, } \\
\text { mean } \pm \text { s.e.m.) }\end{array}$ & $90(80.5 \pm 2.4)$ & $80(68.5 \pm 5.4)$ & $0.0757^{*}$ & $90(76.0 \pm 5.5)$ & $85(70.2 \pm 10.1)$ & $0.7930^{*}$ \\
\hline PR H-score (median, mean \pm s.e.m.) & $245(220.5 \pm 7.9)$ & $190(179.6 \pm 16.3)$ & $0.0323^{*}$ & $245(211.7 \pm 17.4)$ & $185(181.5 \pm 30.4)$ & $0.4441^{*}$ \\
\hline \multicolumn{7}{|l|}{ HER2 status (\%) } \\
\hline Negative & $101(100)$ & $40(100)$ & N/A & $29(100)$ & $12(100)$ & N/A \\
\hline Positive & $0(0)$ & $0(0)$ & & $0(0)$ & $0(0)$ & \\
\hline \multicolumn{7}{|l|}{ Biopsy site (\%) } \\
\hline Absent & $20(20)$ & $14(35)$ & 0.0796 ** & $4(14)$ & $3(25)$ & $0.3978^{* *}$ \\
\hline Present & $81(80)$ & $26(65)$ & & $25(86)$ & $9(75)$ & \\
\hline \multicolumn{7}{|l|}{ Cellular stroma (\%) } \\
\hline Absent & $88(87)$ & $16(40)$ & $<0.0001^{* *}$ & $24(83)$ & $4(33)$ & $0.0036^{* *}$ \\
\hline Present & $13(13)$ & $24(60)$ & & $5(17)$ & $8(67)$ & \\
\hline \multicolumn{7}{|l|}{ Inflammatory cells (\%) } \\
\hline Absent & $88(87)$ & $20(50)$ & $<0.0001^{* *}$ & $24(83)$ & $5(42)$ & $0.0201 * *$ \\
\hline Present & $13(13)$ & $20(50)$ & & $5(17)$ & $7(58)$ & \\
\hline
\end{tabular}

Abbreviations: ER, estrogen receptor; H-score, histological score; HPF, high-power field; NST, no special type; PR, progesterone receptor; s.e.m., standard error of the mean.

*Student's $t$-test or Kruskal-Wallis test.

$* * \chi^{2}$-test.

manufacturer's recommendations using ultraVIEW ${ }^{\mathrm{TM}}$ Red and ultraVIEW ${ }^{\mathrm{TM}}$ DAB detection systems with hematoxylin counterstain for pancytokeratin and
Ki-67, respectively. A negative control was done in each case by omission of the primary antibodies. Normal human tonsil was used as a positive control. 

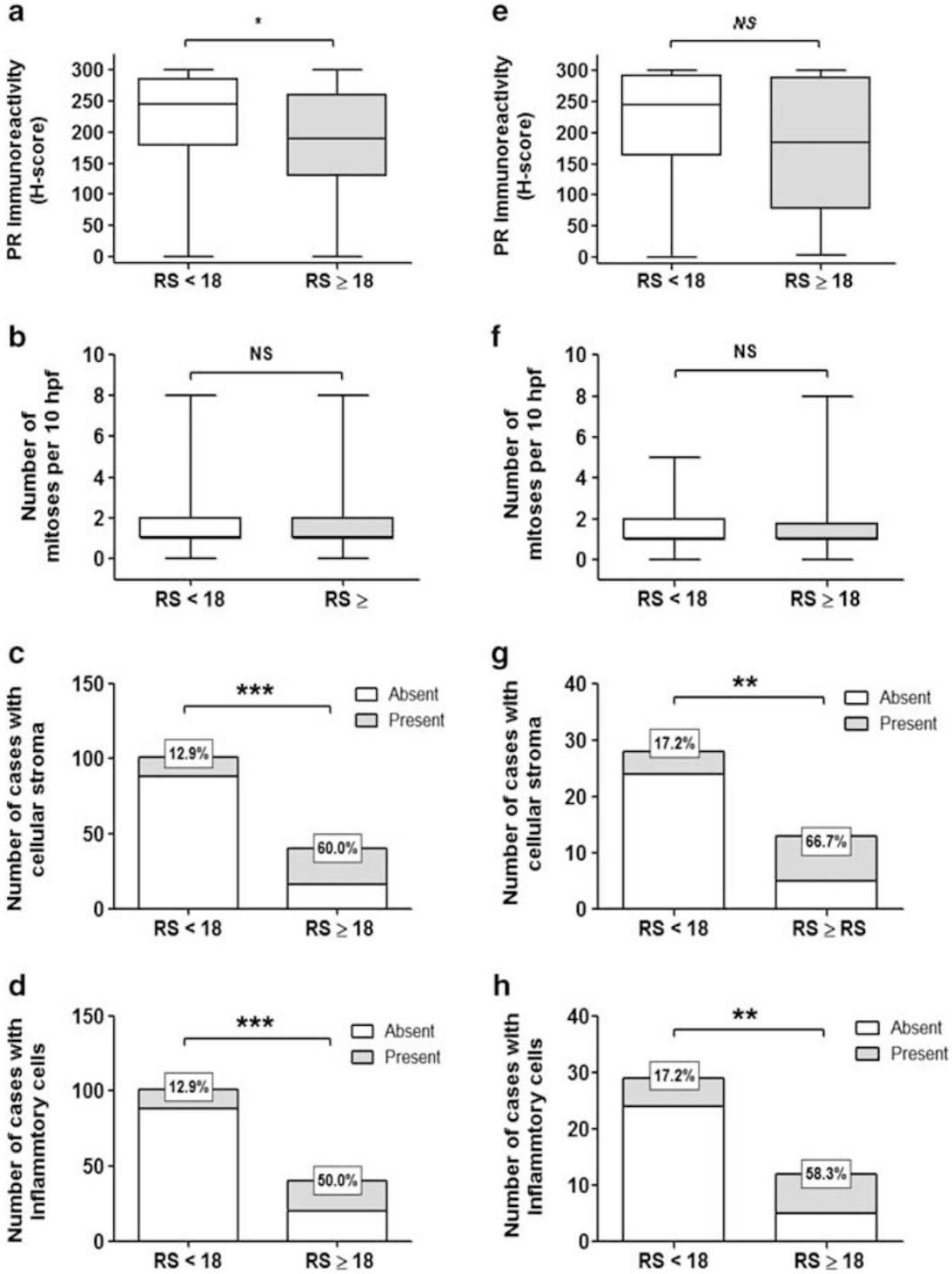

Figure 1 Comparison of progesterone receptor (PR) immunoreactivity (a, e), the number of mitoses per 10 high-power fields in the carcinoma cells $(\mathbf{b}, \mathbf{f})$, the presence of cellular tumor stroma (c and $\mathbf{g}$ ) and presence of inflammatory cells intimately associated with tumor cells (d and h) in low-grade invasive breast carcinomas (a-d) and special type (tubular, cribriform and mucinous) invasive breast carcinoma (e-h). $\left({ }^{* *} P<0.001\right.$; ${ }^{*} P<0.01,{ }^{*} P<0.05$; NS, not significant; Mann-Whitney test, Student's $t$-test and $\chi^{2}$ test).

The areas of cancers showing the highest numbers of Ki-67-positive cancer and stromal cells were identified at low-power magnification. Three representative images of tumor and/or tumor stroma showing the highest numbers of Ki-67-positive cells were obtained using a digital camera. Each image taken at a magnification of $\times 200$ represented an area measuring $0.6554 \mathrm{~mm}^{2}$. Ki-67-positive stromal/ inflammatory (pancytokeratin-negative) and cancer (pancytokeratin-positive) cells were counted manually and the mean values of the counts were obtained. As samples used for Oncotype DX testing do not undergo microdissection of tumor cells separating them from stromal/inflammatory cells, results were expressed as the number of Ki-67positive tumor and stromal/inflammatory cells per square $\mathrm{mm}$ of tumor tissue.
The clinicopathological features of carcinomas with Recurrence Score $<18$ vs Recurrence Score $\geq 18$ were compared using the Mann-Whitney test, Student's $t$-test and $\chi^{2}$ test, when appropriate. The correlation between ER and PR H-score and Oncotype DX ER and PR score values (available in 123 cases) was assessed using the Spearman' test. Statistical significance was determined if the two-sided $P$-value of a test was $<0.05$. Computations were performed using the Graphpad Prizm (Version 5, GraphPad Software, San Diego, CA. USA) software.

\section{Results}

In all, $101(72 \%)$ and $40(28 \%)$ cases showed Recurrence Score $<18$ and $\geq 18$, respectively. Of 

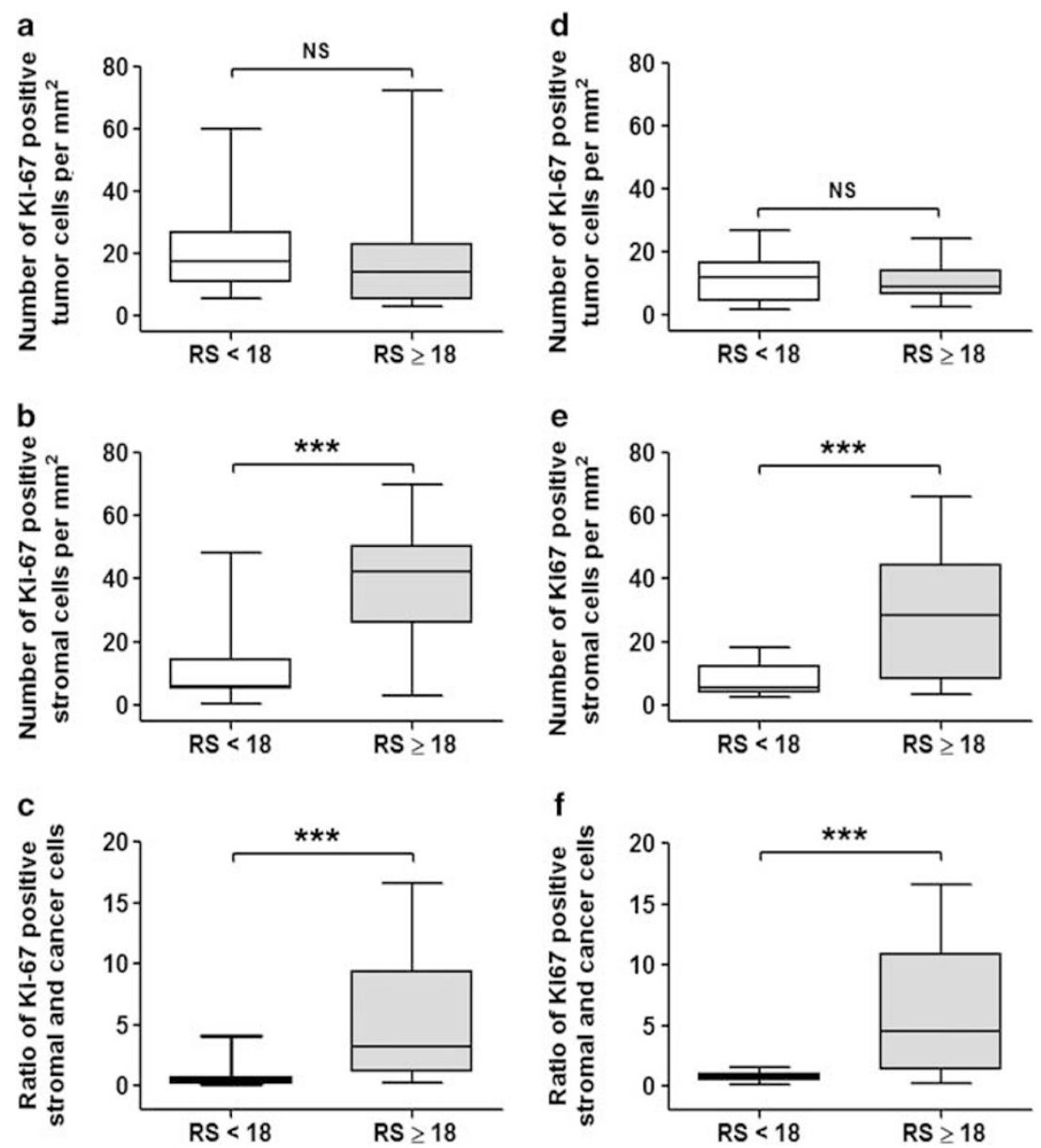

Figure 2 Comparison of the number of Ki-67-positive carcinoma cells (a, d), Ki-67-positive stromal/inflmammatory cells (b, e), and the ratio of Ki-67-positive stromal/carcinoma cells (c,f) in low-grade invasive breast carcinomas (a-c) and special type (tubular, cribriform and mucinous) invasive breast carcinoma (d-f). $\left({ }^{* *} P<0.001\right.$; NS, not significant; Student’s $t$-test).

note, 12 of 41 (29\%) special type (tubular, cribriform and mucinous) carcinomas showed Recurrence Score $\geq 18$. The correlation of clinicopathological tumor features and Recurrence Score is summarized in Table 2 and Figure 1. When all carcinomas were analyzed, those associated with Recurrence Score $\geq 18$ showed significantly lower PR H-score values, increased stromal cellularity and presence of inflammatory cells. There was a statistically significant negative correlation between Oncotype DX PR scores and Recurrence Score results $(r=-6397$, $P<0.0001$, Spearman's test). Although we found a significant positive correlation between Oncotpye DX PR score and PR H-score results $(r=0.4392$, $P<0.0001$, Spearman's test), the correlation between Recurrence Score and PR H-score was less robust ( $r=-1574, \quad P=0.0633$, Spearman's test). Among invasive carcinomas of special types, only increased stromal cellularity $(P=0.0036)$ and the presence of inflammatory cells $(P=0.0201)$ were associated with Recurrence Score $\geq 18$.

Double immunohistochemical stains showed no significant difference in the number of Ki-67positive tumor cells per square $\mathrm{mm}$ of tumor tissue between cases with Recurrence Score $\geq 18$ vs Recurrence Score $<18(16.5 \pm 2.5$ vs $20.4 \pm 2.1$; $\mathrm{p}=0.2388$, Student's $t$-test; Figures $2 \mathrm{a}$ and 3 ). In contrast, the number of stromal/inflammatory Ki-67positive cells was significantly higher in cases associated with Recurrence Score $\geq 18 \quad(37.2 \pm 3.4$ vs $10.4 \pm 1.6$ in cases with RS $<18, P<0.0001$, Student's $t$-test; Figure 2b). Similarly, when special type carcinomas were analyzed separately, we found no significant difference between the number of $\mathrm{Ki}$ 67-positive tumor cells between cases showing Recurrence Score $\geq 18$ vs Recurrence Score $<18$ $(11.0 \pm 1.8$ vs $11.1 \pm 1.9 ; \mathrm{p}=0.9430$, Student's $t$-test; Figure 2d). In contrast, the number of stromal/ inflammatory Ki-67-positive cells was significantly higher in cases associated with Recurrence Score $\geq 18$ (29.6 \pm 5.4 vs $8.2 \pm 1.3$ in cases with Recurrence Score $<18, \mathrm{p}=0.0002$, Student's $t$-test; Figure 2e). The ratio of Ki-67-positive stromal/inflammatory and tumor cells was significantly higher in cancers associated with Recurrence Score $\geq 18$ compared with those with Recurrence Score $<18$ among all cases (5.49 \pm 0.92 vs $0.63 \pm 0.13, P<0.0001$, Student's $t$-test, Figure 2c) and when special type carcinomas were analyzed separately $(6.16 \pm 1.54$ vs $0.74 \pm 0.08, P<0.0001$, Student's $t$-test, Figure $2 \mathrm{f}$ ). 

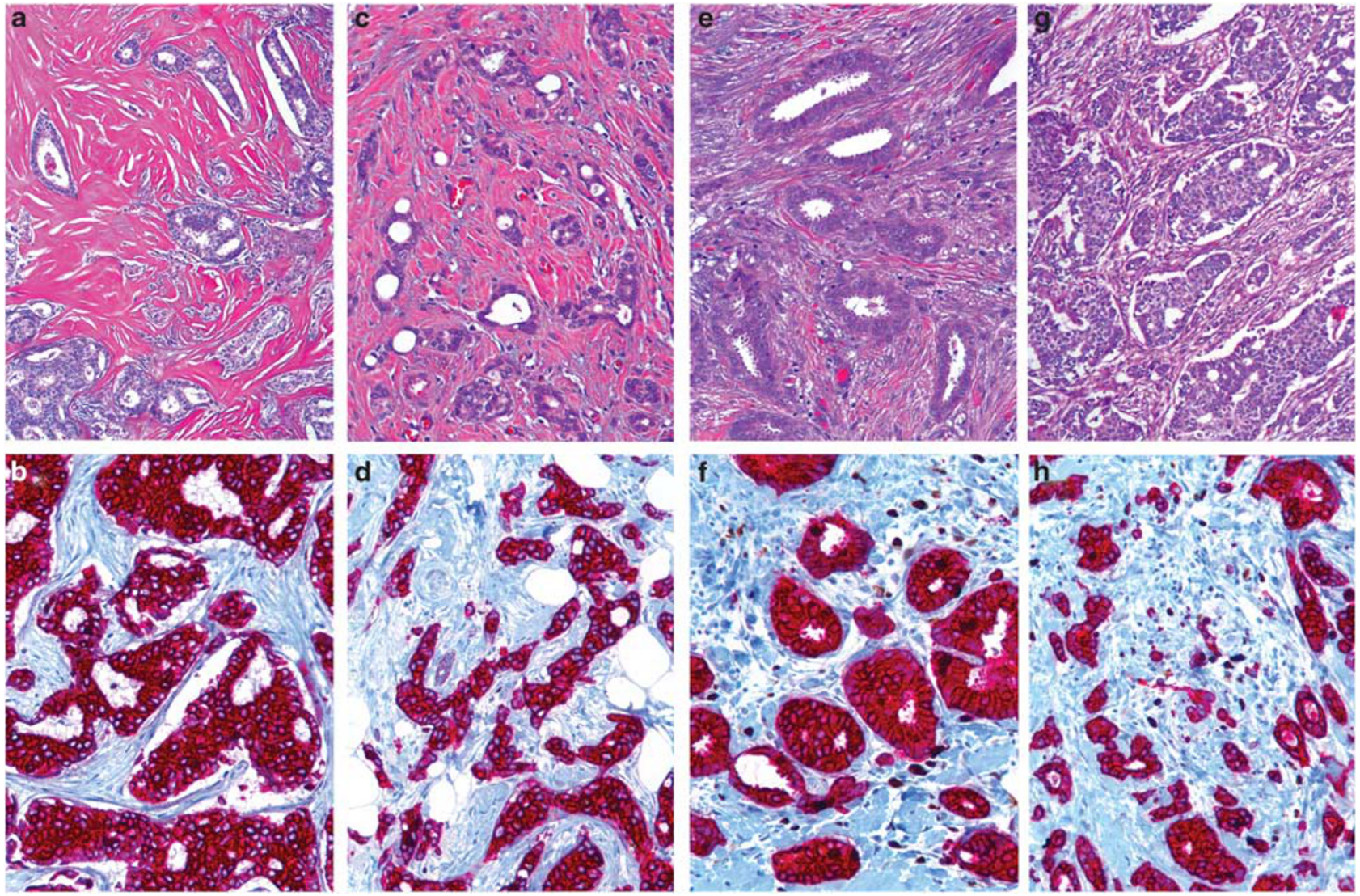

Figure 3 (a, b) Low-grade invasive ductal (no special type) carcinoma with an Oncotype DX Recurrence Score (RS) of 12 . Note that the tumor stroma is fibrotic, sparsely cellular and lack significant proliferation (as determined by Ki-67 immunohistochemistry). (c, d) Lowgrade invasive ductal (no special type) carcinoma with an Oncotype DX RS of 15. The tumor stroma is more cellular, but without significant proliferation (as determined by Ki-67 immunohistochemistry). (e, f) Low-grade invasive ductal (no special type) carcinoma with an Oncotype DX RS of 24. Note that the tumor stroma is cellular with spindled stromal and inflammatory cells. Ki-67 immunostain shows significant proliferative activity within the tumor stroma. (g, h) Low-grade invasive ductal (no special type) carcinoma with an Oncotype DX RS of 21. Note that the tumor stroma is cellular with spindled stromal and inflammatory cells. Ki-67 immunostain shows significant proliferative activity within the tumor stroma. (a, c, e, g: Hematoxylin and eosin stain; b, d, f, h: double immunohistochemical stains for pancytokeratin (red) and Ki-67 (brown)).

We found a statistically significant correlation between Recurrence Score and the number of Ki-67positive stromal/inflammatory cells per square $\mathrm{mm}$ of tumor $(r=0.6484, P<0.0001$, Spearman's test, Figure $4 \mathrm{a})$ and the ratio of Ki-67-positive stromal/ inflammatory vs tumor cells $(r=0.6460, P<0.0001$, Spearman's test, Figure 4b). No significant correlation was found between the number of Ki-67positive cancer cells per square $\mathrm{mm}$ and Recurrence Score. Among all cases, a Ki-67-positive stromal/ tumor cell ratio of $>1$ predicted Recurrence Score $\geq 18$ with a sensitivity and specificity of 0.7667 and 0.8857 , respectively, and showed an area under the curve of 0.8967 on receiver operator curve (ROC) analysis $(P<0.0001$, Figure $4 \mathrm{c})$. When special type carcinomas were analyzed separately, a Ki-67-positive stromal/tumor cell ratio of $>1$ predicted Recurrence Score $\geq 18$ with a sensitivity and specificity of 0.7500 and 0.8621 , respectively, and showed an area under the curve of 0.8851 on ROC analysis $(P=0.0001$, Figure $4 d)$.

\section{Discussion}

The main finding of this study is that low-grade invasive breast carcinomas showing intermediate or high Recurrence Score are associated with a proliferative, cellular stroma and/or presence of inflammatory cells intimately associated with the tumor cells. Regarding the possible effect of inflammation on the Recurrence Score, one previous study suggested that in some cases a high Recurrence Score may be more related to peritumoral inflammatory response rather than the tumor itself. ${ }^{55}$ Recent metaanalyses of microarray-based expression profiling studies have demonstrated that the prognostic impact of the molecular signatures investigated, including the Recurrence Score, mainly stems from the proliferation-related genes. ${ }^{56,57}$ The Recurrence Score calculation is also heavily weighted for a group of five proliferation-related markers (Ki-67, STK15, Survivin, CylcinB1, MYBL2). In fact, Baehner et $a l^{45}$ have previously shown that the 


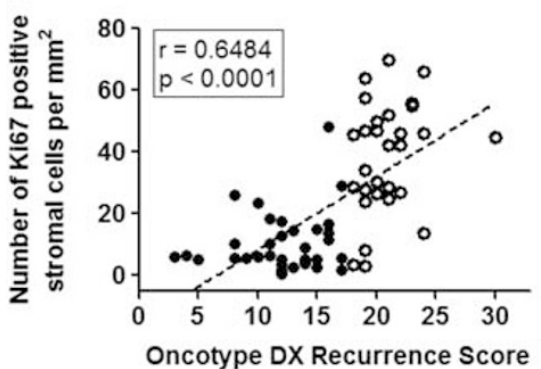

C

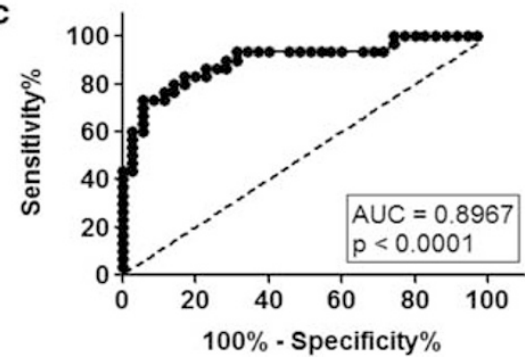

b

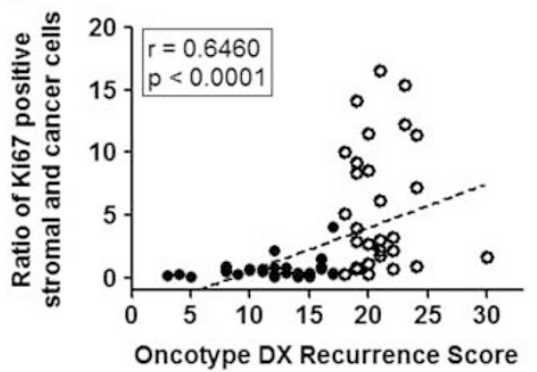

d

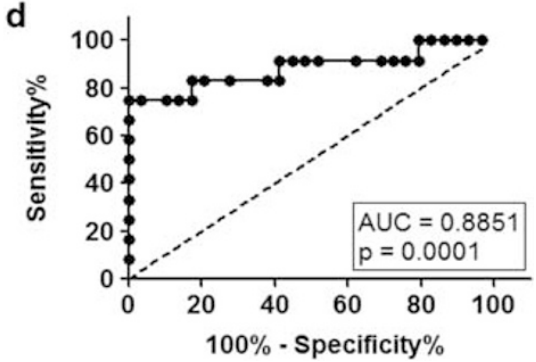

Figure 4 (a) Correlation of the number of proliferating Ki-67-positive stromal/inflammatory cells and Oncotype DX Recurrence Score (RS) in low-grade invasive breast carcinomas (Spearman's test). (b). Correlation of the ratio of Ki-67-positive stromal/inflammatory vs cancer cells and Oncotype DX RS in low-grade invasive breast carcinomas (Spearman's test). (c, d) Receiver operator curve (ROC) for the ratio of Ki-67-positive stromal/inflammatory vs cancer cells to predict an RS of $\geq 18$ in low-grade invasive breast carcinomas (c) and special type (tubular, cribriform and mucinous) invasive breast carcinomas (d).

presence of a biopsy site associated with increased cell proliferation can alter the Recurrence Score. As Oncotype DX is not an in situ test it suffers from the inherent limitations present when a portion of tissue is used that contains both invasive cancer and associated stromal/inflammatory cells. The intimately admixed inflammatory cells and/or stromal proliferation are included in the assay and are not controlled for when the Recurrence Score is calculated. As the Recurrence Score heavily depends on the expression levels of proliferation markers, our findings suggest that the presence of a tumor-associated proliferating cellular stroma and/or inflammatory cells likely contribute to the apparently increased Recurrence Score seen in these cases. Although not examined in this study, a similar effect cannot be excluded in intermediate grade tumors, especially those with moderate nuclear pleomorphism and low mitotic activity.

Traditionally, treatment decisions for patients with breast cancer are based on clinicopathological tumor features and patient characteristics. One of the most established and validated histopathological prognostic feature is tumor grade, as determined by the modified combined histological grading system. ${ }^{9-11,54}$ A compelling body of evidence suggests that histological grade can accurately predict tumor behavior, particularly in early stage, small tumors. ${ }^{10,12,17,29}$ Recent gene expression profiling studies of breast cancer have shown that tumors of different histological grades show distinct molecular profiles, suggesting that histological grade is indeed an accurate morphological reflection of the molecular makeup of breast cancers ${ }^{14,36}$ and emphasized its relevance in breast cancer biology and behavior. ${ }^{58,59}$

Several large studies have shown that patients with early stage, low-grade invasive breast carcinoma have an excellent outcome with over 95\% survival. ${ }^{29,49,60}$ Although special type carcinomas were largely neglected in the development of molecular assays, this issue is further highlighted by the unexpectedly high proportion of special type carcinomas showing intermediate or high Recurrence Score results. Baehner et $a l^{61}$ have also reported that up to one third of tubular, cribriform mucinous carcinomas show intermediate or high Recurrence Score. Although these findings might be interpreted as a reason to suggest Oncotype DX testing in special type carcinomas, in our opinion the available clinical experience, indicating an excellent prognosis in these cases, ${ }^{26-28}$ suggest otherwise.

Although it is often stated that the molecular tests help in 'individualizing' therapy according to the biological features of cancer, the prognostic/predictive value of these tests are in fact based on the population data (ie, data based on large numbers of patients in several studies). Although there have been substantial efforts to clinically validate the ability of Recurrence Score to predict outcome and likelihood of response to therapy in large series of patients with early stage, ER-positive breast cancer, there are little data to show that the Recurrence Score is in fact reflective of the recurrence risk and/ or likelihood of response to chemotherapy in an individual patient. Associations between various 
clinicopathological tumor features and Recurrence Score have been examined in a limited number of studies, ${ }^{44,62-64}$ some even suggesting that Recurrence Score can be estimated based on histopathological features, ${ }^{44,62,63}$ but little attention has been paid to the 'discrepant' cases. Similar to our experience, Allison et al $^{44}$ have also observed that a significant number of breast cancers that were expected to receive a low Recurrence Score based on clinicopathological features resulted in intermediate or high Recurrence Score, noting that little has been done to investigate the possibility that some cases may have a falsely low or high Recurrence Score when compared with what would be expected based on routine pathological parameters.

Similar to our results, several prior studies have shown that low levels of PR expression significantly correlate with increased Recurrence Score in breast cancers. ${ }^{44,62,63,65,66}$ Several studies have shown that ER-positive breast cancers with low or absent PR expression have a worse prognosis ${ }^{67}$ and benefit less from tamoxifen therapy compared with tumors showing high levels of PR expression. ${ }^{68-70}$ As the predictive value of the Oncotype DX test is based on the assumption that patients receive adjuvant antihormonal therapy and PR expression levels, with an overall range of 1000 -fold in the assay, have a significant role in the calculation of the Recurrence Score, these results are not surprising. In fact, Allison et $a l^{44}$ found that in addition to histological grade, PR levels can segregate breast carcinomas into different Recurrence Score categories.

It is well known that tumor-stroma interactions have a significant role in the tumor development and progression, and alterations in the stromal microenvironment, such as enhanced vasculature, modified extracellular matrix composition, inflammatory cells, and unbalanced protease activity, are essential regulatory factors of the tumor growth and invasion. ${ }^{71-74}$ However, these effects are mainly thought to be mediated by the expression of cytokines and growth factors by the cancer-associated fibroblasts/inflammatory cells and it is unlikely that the proliferative activity of these cells per se has a significant role in these processes. We are aware that the ultimate test to determine whether the low-grade carcinomas with cellular, proliferative stroma and increased Recurrence Score do worse than those without these features would be longterm patient outcome. As the Oncotype DX test was introduced to clinical practice in 2004, at the present time we only have short-term follow-up on the cohort of patients included in the study. Although it is our intention to re-evaluate these data when long-term follow-up becomes available, based on clinical experience, we expect an excellent outcome in this cohort of patients with small, lowgrade, ER-positive and node-negative tumors.

In summary, our study suggests that the presence of a mitotically active, cellular tumor stroma and inflammatory cells associated with the tumor in low-grade invasive breast carcinomas may contribute to Oncotype DX Recurrence Score results, indicating an apparently increased risk of recurrence. Careful pathological assessment and correlation with histopathological features in such 'discordant' cases may help in determining the appropriate patient management. In addition, the Recurrence Score should be used with caution in patients with special type carcinomas until more information is available. Given the inherent characteristics of the assay, clinicians and pathologists should be alert to the possibility that the Recurrence Score may not be representative of the true cancer biology in cases when there is an associated cellular tumor stroma and/or abundant admixed inflammation in a case, emphasizing the important role of careful histopathological assessment of every breast cancer.

\section{Disclosure/conflict of interest}

Drs Acs, Loftus and Laronga are the Speakers' Bureau for Genomic Health.

\section{References}

1 Simpson PT, Reis-Filho JS, Gale T, et al. Molecular evolution of breast cancer. J Pathol 2005;205:248-254.

2 Weigelt B, Reis-Filho JS. Histological and molecular types of breast cancer: is there a unifying taxonomy? Nat Rev Clin Oncol 2009;6:718-730.

3 Weigelt B, Baehner FL, Reis-Filho JS. The contribution of gene expression profiling to breast cancer classification, prognostication and prediction: a retrospective of the last decade. J Pathol 2010;220:263-280.

4 Azzopardi JG, Ahmed A, Millis RR. Problems in Breast Pathology. WB Saunders: London, 1979.

5 Page DL, Anderson TJ. Diagnostic Histopathology of the Breast. Churchill Livingstone: Edinburgh, 1987.

6 Tavassoli FA. Pathology of the Breast. Appleton \& Lange: Stamford, 1999.

7 Rosen PP, Oberman HA. Tumors of the Mammary Gland. Armed Forces Institute of Pathology: Washington, DC, 1993.

8 Rosen PP. Rosen's Breast Pathology. Williams \& Wilkins: Philadelphia, 2001.

9 Elston CW, Ellis IO. Assessment of histologic grade In: Elston CW, Ellis IO (eds). The Breast 3rd edn. Churchill Livingstone: Edinburgh, 1998, pp 365-384.

10 Elston CW, Ellis IO. Pathological prognostic factors in breast cancer. I. The value of histological grade in breast cancer: experience from a large study with longterm follow-up. Histopathology 2002;41:154-161.

11 Elston CW, Ellis IO. Pathological prognostic factors in breast cancer. I. The value of histological grade in breast cancer: experience from a large study with longterm follow-up. Histopathology 1991;19:403-410.

12 Sundquist M, Thorstenson S, Brudin L, et al. Applying the Nottingham Prognostic Index to a Swedish breast cancer population. South East Swedish Breast Cancer Study Group. Breast Cancer Res Treat 1999;53:1-8.

13 Saimura M, Fukutomi T, Tsuda H, et al. Prognosis of a series of 763 consecutive node-negative invasive breast 
cancer patients without adjuvant therapy: analysis of clinicopathological prognostic factor. J Surg Oncol 1999;71:101-105.

14 Rakha EA, Reis-Filho JS, Baehner F, et al. Breast cancer prognostic classification in the molecular era: the role of histological grade. Breast Cancer Res 2010;12:207.

15 Lundin J, Lundin M, Holli K, et al. Omission of histologic grading from clinical decision making may result in overuse of adjuvant therapies in breast cancer: results from a nationwide study. J Clin Oncol 2001;19:28-36.

16 Simpson JF, Gray R, Dressler LG, et al. Prognostic value of histologic grade and proliferative activity in axillary node-positive breast cancer: results from the Eastern Cooperative Oncology Group Companion Study, EST 4189. J Clin Oncol 2000;18:2059-2069.

17 Frkovic-Grazio S, Bracko M. Long term prognostic value of Nottingham histological grade and its components in early (pT1N0M0) breast carcinoma. J Clin Pathol 2002;55:88-92.

18 Anderson TJ, Alexander FE, Lamb J, et al. Pathology characteristics that optimize outcome prediction of a breast screening trial. Br J Cancer 2000;83:487-492.

19 Blamey RW, Hornmark-Stenstam B, Ball G, et al. ONCOPOOL-a European database for 16944 cases of breast cancer. Eur J Cancer 2010;46:56-71.

20 Mirza AN, Mirza NQ, Vlastos G, et al. Prognostic factors in node-negative breast cancer: a review of studies with sample size more than 200 and follow-up more than 5 years. Ann Surg 2002;235:10-26.

21 Warwick J, Tabar L, Vitak B, et al. Time-dependent effects on survival in breast carcinoma: results of 20 years of follow-up from the Swedish Two-County Study. Cancer 2004;100:1331-1336.

22 Blamey RW, Ellis IO, Pinder SE, et al. Survival of invasive breast cancer according to the Nottingham Prognostic Index in cases diagnosed in 1990-1999. Eur J Cancer 2007;43:1548-1555.

23 Haybittle JL, Blamey RW, Elston CW, et al. A prognostic index in primary breast cancer. Br J Cancer 1982;45:361-366.

24 Todd JH, Dowle C, Williams MR, et al. Confirmation of a prognostic index in primary breast cancer. Br J Cancer 1987;56:489-492.

25 Goldhirsch A, Ingle JN, Gelber RD, et al. Thresholds for therapies: highlights of the St Gallen International Expert Consensus on the primary therapy of early breast cancer 2009. Ann Oncol 2009;20:1319-1329.

26 Page DL, Simpson JF. Pathology of preinvasive and excellent-prognosis breast cancer. Curr Opin Oncol 2000;12:526-531.

27 Page DL, Anderson TJ, Sakamoto G. Infiltrating carcinoma: Major histologic types. In: Page DL, Anderson TJ (eds). Diagnostic Histopathology of the Breast. WB Saunders: London, 1987, pp 193-235.

28 Simpson JF, Page DL. Pathology of preinvasive and excellent prognosis breast cancer. Curr Opin Oncol 2001;13:426-430.

29 Rakha EA, El-Sayed ME, Lee $\mathrm{AH}$, et al. Prognostic significance of Nottingham histologic grade in invasive breast carcinoma. J Clin Oncol 2008;26:3153-3158.

30 Acs G. Invasive carcinoma, special types In: Lawton TJ (ed) Breast Cambridge Illustrated Surgical Pathology. Cambridge University Press: Cambridge, 2009, pp 137-184.

31 Paik S, Shak S, Tang G, et al. A multigene assay to predict recurrence of tamoxifen-treated, node-negative breast cancer. N Engl J Med 2004;351:2817-2826.
32 Perou CM, Sorlie T, Eisen MB, et al. Molecular portraits of human breast tumours. Nature 2000; 406:747-752.

33 Sorlie T, Perou CM, Tibshirani R, et al. Gene expression patterns of breast carcinomas distinguish tumor subclasses with clinical implications. Proc Natl Acad Sci USA 2001;98:10869-10874.

34 Sorlie T, Tibshirani R, Parker J, et al. Repeated observation of breast tumor subtypes in independent gene expression data sets. Proc Natl Acad Sci USA 2003;100:8418-8423.

35 van de Vijver MJ, He YD, Van't Veer LJ, et al. A geneexpression signature as a predictor of survival in breast cancer. N Engl J Med 2002;347:1999-2009.

36 Sotiriou C, Wirapati P, Loi S, et al. Gene expression profiling in breast cancer: understanding the molecular basis of histologic grade to improve prognosis. J Natl Cancer Inst 2006;98:262-272.

37 Wang Y, Klijn JG, Zhang Y, et al. Gene-expression profiles to predict distant metastasis of lymph-nodenegative primary breast cancer. Lancet 2005;365: 671-679.

38 Potti A, Dressman HK, Bild A, et al. Genomic signatures to guide the use of chemotherapeutics. Nat Med 2006;12:1294-1300.

39 Habel LA, Shak S, Jacobs MK, et al. A populationbased study of tumor gene expression and risk of breast cancer death among lymph node-negative patients. Breast Cancer Res 2006;8:R25.

40 Esteva FJ, Sahin AA, Cristofanilli M, et al. Prognostic role of a multigene reverse transcriptase-PCR assay in patients with node-negative breast cancer not receiving adjuvant systemic therapy. Clin Cancer Res 2005;11:3315-3319.

41 Gianni L, Zambetti M, Clark K, et al. Gene expression profiles in paraffin-embedded core biopsy tissue predict response to chemotherapy in women with locally advanced breast cancer. J Clin Oncol 2005; 23:7265-7277.

42 Paik S, Tang G, Shak S, et al. Gene expression and benefit of chemotherapy in women with node-negative, estrogen receptor-positive breast cancer. J Clin Oncol 2006;24:3726-3734.

43 Harris L, Fritsche H, Mennel R, et al. American Society of Clinical Oncology 2007 update of recommendations for the use of tumor markers in breast cancer. J Clin Oncol 2007;25:5287-5312.

44 Allison KH, Kandalaft PL, Sitlani CM, Dintzis SM, Gown AM. Routine pathologic parameters can predict Oncotype DX(TM) recurrence scores in subsets of ER positive patients: who does not always need testing? Breast Cancer Res Treat 2011, E-pub ahead of print.

45 Baehner F, Quale C, Pomeroy C, et al. Biopsy cavities in breast cancer specimens: their impact on quantitative RT-PCR gene expression profiles and recurrence risk assessment (abstract). Mod Pathol 2008;22: 28A-29A.

46 Diab SG, Clark GM, Osborne CK, et al. Tumor characteristics and clinical outcome of tubular and mucinous breast carcinomas. J Clin Oncol 1999; 17:1442-1448.

47 Page DL, Dixon JM, Anderson TJ, et al. Invasive cribriform carcinoma of the breast. Histopathology 1983;7:525-536.

48 Venable JG, Schwartz AM, Silverberg SG. Infiltrating cribriform carcinoma of the breast: a distinctive clinicopathologic entity. Hum Pathol 1990;21:333-338. 
49 Rakha EA, Lee AH, Evans AJ, et al. Tubular carcinoma of the breast: further evidence to support its excellent prognosis. J Clin Oncol 2010;28:99-104.

50 Javid SH, Smith BL, Mayer E, et al. Tubular carcinoma of the breast: results of a large contemporary series. Am J Surg 2009;197:674-677.

51 Hanagiri T, Ono K, Baba T, et al. Clinicopathologic characteristics of mucinous carcinoma of the breast. Int Surg 2010;95:126-129.

52 Pinder SE, Elston CW, Ellis IO. Invasive carcinomausual histologic types. In: Elston CW, Ellis IO (eds). The Breast, 3rd edn. Churchill Livingstone: Edinburgh, 1998, pp 283-337.

53 McCarty Jr KS, Woodard BH, Nichols DE, Wilkinson W, McCarty Sr KS. Comparison of biochemical and histochemical techniques for estrogen receptor analyses in mammary carcinoma. Cancer 1980;46: 2842-2845.

54 Elston CW, Ellis IO, Goulding $\mathrm{H}$, et al. Role of pathology in the prognosis and management of breast cancer In: Elston CW, Ellis IO (eds) The Breast. Churchill Livingstone: Edinburgh, 1998, pp 385-433.

55 Grimes M, Coad J, Oliviero B, et al. Comparison of Oncotype DX recurrence score and standard immunohistochemical prognostic markers (abstract). Mod Pathol 2007;20:33A.

56 Wirapati P, Sotiriou C, Kunkel S, et al. Meta-analysis of gene expression profiles in breast cancer: toward a unified understanding of breast cancer subtyping and prognosis signatures. Breast Cancer Res 2008; 10:R65.

57 Desmedt C, Haibe-Kains B, Wirapati P, et al. Biological processes associated with breast cancer clinical outcome depend on the molecular subtypes. Clin Cancer Res 2008;14:5158-5165.

$58 \mathrm{Yu} \mathrm{K}$, Lee CH, Tan PH, et al. A molecular signature of the Nottingham prognostic index in breast cancer. Cancer Res 2004;64:2962-2968.

$59 \mathrm{Lu} \mathrm{X}, \mathrm{Lu} \mathrm{X}$, Wang ZC, et al. Predicting features of breast cancer with gene expression patterns. Breast Cancer Res Treat 2008;108:191-201.

60 Henson DE, Ries L, Freedman LS, et al. Relationship among outcome, stage of disease, and histologic grade for 22,616 cases of breast cancer. The basis for a prognostic index. Cancer 1991;68:2142-2149.

61 Baehner FL, Watson D, Bollard JT, et al. Gene expression by standardized quantitative RT-PCR in the special histologic subtypes of estrogen receptor positive invasive breast cancer (abstract). Breast Cancer Res Treat 2007;106:S135.
62 Flanagan MB, Dabbs DJ, Brufsky AM, et al. Histopathologic variables predict Oncotype DX recurrence score. Mod Pathol 2008;21:1255-1261.

63 Geradts J, Bean SM, Bentley RC, et al. The oncotype DX recurrence score is correlated with a composite index including routinely reported pathobiologic features. Cancer Invest 2010;28:969-977.

64 Wolf I, Ben-Baruch N, Shapira-Frommer R, et al. Association between standard clinical and pathologic characteristics and the 21-gene recurrence score in breast cancer patients: a population-based study. Cancer 2008;112:731-736.

65 Auerbach J, Kim M, Fineberg S. Can features evaluated in the routine pathologic assessment of lymph node-negative estrogen receptor-positive stage I or II invasive breast cancer be used to predict the Oncotype DX recurrence score? Arch Pathol Lab Med 2010;134:1697-1701.

66 Tang P, Wang J, Hicks DG, et al. A lower Allred score for progesterone receptor is strongly associated with a higher recurrence score of 21-gene assay in breast cancer. Cancer Invest 2010;28:978-982.

67 Liu S, Chia SK, Mehl E, et al. Progesterone receptor is a significant factor associated with clinical outcomes and effect of adjuvant tamoxifen therapy in breast cancer patients. Breast Cancer Res Treat 2010;119:53-61.

68 Arpino G, Weiss H, Lee AV, et al. Estrogen receptorpositive, progesterone receptor-negative breast cancer: association with growth factor receptor expression and tamoxifen resistance. J Natl Cancer Inst 2005;97: 1254-1261.

69 Cui X, Schiff R, Arpino G, et al. Biology of progesterone receptor loss in breast cancer and its implications for endocrine therapy. J Clin Oncol 2005;23: 7721-7735.

70 Stendahl M, Ryden L, Nordenskjold B, et al. High progesterone receptor expression correlates to the effect of adjuvant tamoxifen in premenopausal breast cancer patients. Clin Cancer Res 2006;12:4614-4618.

71 Chung LW, Hsieh CL, Law A, et al. New targets for therapy in prostate cancer: modulation of stromalepithelial interactions. Urology 2003;62:44-54.

72 Sung SY, Chung LW. Prostate tumor-stroma interaction: molecular mechanisms and opportunities for therapeutic targeting. Differentiation 2002;70:506-521.

73 Mueller MM, Fusenig NE. Tumor-stroma interactions directing phenotype and progression of epithelial skin tumor cells. Differentiation 2002;70:486-497.

74 Ingber DE. Cancer as a disease of epithelial-mesenchymal interactions and extracellular matrix regulation. Differentiation 2002;70:547-560. 